\title{
MEMÓRIAS E NARRATIVAS DE PROFESSORAS "NORMALISTAS" DO INSTITUTO DE EDUCAÇÃO/RJ
}

\author{
Vera Maria Ramos de Vasconcellos ${ }^{* *}$
}

\begin{abstract}
RESUMO: O trabalho analisa o pensamento produzido na vida cotidiana urbana e na formação de normalistas do Instituto de Educação de 1948. É inspirado na leitura do livro de Zilá Simas Enéas, ex-aluna daquela instituição de ensino: Era uma vez no Instituto de Educação (editado em 1997, pela CNEL/RJ). De modo particular, neste trabalho são analisadas as memórias e narrativas daquelas meninas normalistas - hoje senhoras com mais de 80 anos -, suas relações com a educação, a escola, a infância e a cidade do Rio de Janeiro, antiga capital do país (Distrito Federal), depois Estado da Guanabara e, mais tarde, município do Rio de Janeiro. As interferências produzidas por essas imagens/memórias/concepções com outras configuraçôes discursivas da sociedade, ao longo da história, são questôes que nortearam a pesquisa. A análise destaca a disseminação de valores educacionais, éticos e estéticos em um tempo em que se expressavam projetos diversos, orientados para o estabelecimento de uma "ordem moderna" no país, na geração feminina do "Estado novo". Com este trabalho, buscamos compreender o que él foi ser professora.
\end{abstract}

Palavras-chave: Memória. Narrativa. Normalista. Professora.

* Este artigo é resultado de uma pesquisa desenvolvida com apoio das alunas de graduação, do curso de Pedagogia da Universidade do Estado do Rio de Janeiro (Uerj): Ana Paula da Silva Pereira, Claudia Lopes Rocha, Lívia dos Santos Xavier Mendonça, Manuela da Costa Monteiro e Sylvia Amélia Braga Silva.

** Doutora em Social Developmental Psychology Department e professora titular do Departamento de Estudos da Infância e do Programa de Pós-Graduação em Educação da Uerj. E-mail:vmrv@opelink.com.br 
Memórias e narrativas de professoras "normalistas" do Instituto de Educação/RJ

\title{
MEMories AND NARRATIVES FROM THE INSTITUTO DE EDUCAÇÃO OF RIO DANEIRO CITY'S ELEMENTARY SCHOOL TEACHERS
}

\begin{abstract}
The article analysed the thought produced in every-day urban life and the elementary school teachers' training at the Instituto de Educação of Rio de Janeiro of those teachers who had graduated until 1948. The research is inspired by Zilá Simas Enéas' book: "Once upon a time at the Instituto de Educação" (published by CNEL/RJ in 1997). The writer is an ex-student from that educational institute. The article analysed, particularly, the memories and narratives from those girls, who today are ladies around 80 years old, their ideas about education, school, infancy and the city of Rio de Janeiro. This city was the country's capital (Federal District), then became Guanabara State and latter the city of Rio de Janeiro. The interferences produced by the images/memories/concepts with different discursive configuration about the Brazilian society all over the history were others questions important to this research. The analysis emphasised the educational, ethical and esthetical values, in a different historical period with different projects, all oriented to the country's modernization, in a feminine generation during the Estado Novo period in Brazil. In this article we attempted to understand what is/ was to by a teacher.
\end{abstract}

Key words: Memory. Narrative. Elementary School Teacher.

\section{Introdução}

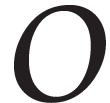

artigo apresenta memórias do dia a dia de uma convivência contínua (sete anos para algumas; para outras, quatro anos) com normalistas formadas no ano de 1948, no Instituto de Educação, na cidade do Rio de Janeiro. Para a realização dos relatos aqui produzidos, lemos, numa disciplina da Faculdade de Educação da Uerj, intitulada Pesquisa e Prática Pedagógica, ${ }^{1}$ o livro Era uma vez no Instituto de Educação, de Zilá Simas Enéas (1997), ex-aluna daquela instituição de ensino. A leitura nos conduziu a outras modalidades metodológicas de investigação, que nos possibilitaram analisar as representaçôes sociais de algumas daquelas meninas normalistas - hoje senhoras com cerca de 80 anos - em suas múltiplas relaçoes. Detalhamos, com maior foco, as questōes relativas à: educação, escola, infância e a própria cidade, antes 
capital do país (Distrito Federal), depois Estado da Guanabara e, mais tarde, município do Rio de Janeiro.

A pesquisa foi construída a partir da análise desenvolvida pelo grupo das alunas/pesquisadoras da Faculdade de Educação da Uerj. A metodologia utilizada incluiu, além da leitura do livro no coletivo do grupo, ${ }^{2}$ a realização de entrevistas individuais (três) e coletivas (grupo de ex-normalistas daquela época ${ }^{3}$ ) com questôes abertas e fechadas, que documentaram histórias de vida dessas professoras, gravadas em áudio e vídeo. Em complementação às entrevistas, foram realizadas análises documentais em duas visitas ao Centro de Memória Institucional (Cemi) do Instituto Superior de Educação do Rio de Janeiro (Iserj). A argumentação teórica foi construída em diálogo com outros textos que abordam o mesmo tema, de forma similar (Machado, 2007; Mignot \& Cunha, 2003; Freitas, 2000) e, também, uma tese de doutorado de Sarita Lea Schaffel (1999).

O foco de nossos estudos está na educação da mulher, assunto que passou a ser alvo das preocupaçōes nacionais somente a partir dos higienistas. Após a Proclamação da República (1889), o ensino passou a ser extensivo às mulheres, fortalecendo a possibilidade de elas ocuparem uma posição profissional. O texto traz a marca da diversidade de vozes que se mesclam nas memórias de nossas entrevistadas, nos recortes da pesquisa e dos autores escolhidos.

A tese de doutorado de Schaffel (op. cit.), que pesquisou a história do Instituto de Educação do Rio de Janeiro e a identidade profissional dos alunos formados nessa instituição de ensino, inspirou o nosso trabalho. Por ela, procuramos conhecer um pouco mais da história dessa instituição, a partir do olhar das ex-normalistas das décadas de 1930, 40 e 50, entrevistadas pela autora. Nosso artigo amplia aquela análise, focando num único grupo (turma de 1948), buscando retratar o olhar de senhoras sobre todo o tempo em que viveram no Instituto. Dizemos "viveram", pois, para essas alunas-mestras, significou muito o período em que fizeram parte do corpo discente daquela instituição; tão importante para elas e para a sociedade daquela época!

O nosso objetivo é buscar, na história dessas ex-alunas, um paralelo para o retrato da educação da época e resgatar, por meio dos relatos das mesmas, o que é ser ou tornar-se professor(a) e o que motivou muitas meninas e alguns (poucos) meninos a escolherem tal 
profissão, dando um sentido particular ao exercício do magistério. Empreendemos, com este artigo, um convite ao leitor para realizar uma viagem no tempo, descobrindo um passado que possa iluminar o nosso presente: "Ao trabalharmos com a memória de um tempo vivido por professoras aposentadas, desvelamos o passado, refletimos sobre o presente, pensando um outro futuro" (Freitas, 2000).

\section{Metodologia}

Inicialmente, o grupo de pesquisa analisou o livro supracitado. Depois, o grupo sentiu necessidade de conhecer a edificação tão efusivamente mencionada na obra. A visita foi realizada em dois momentos, orientada pela professora Heloisa Helena Meirelles, coordenadora do Cemi (Iserj). O Cemi reúne documentos históricos da instituição num só local, para acesso de alunos, professores e pesquisadores em geral, entendendo-se como documento qualquer material referente à educação, desde 1880 .

Num terceiro momento, o grupo de pesquisa realizou entrevistas individuais com duas normalistas de 1948, além da autora do livro-base e uma entrevista coletiva num almoço de confraternização, onde estiveram presentes cerca de cinquenta ex-alunas das sete turmas de 1948. Com as ex-normalistas entrevistadas, procuramos investigar suas avaliações sobre a representação do Instituto de Educação em suas vidas e na sociedade, a formação de professores da época, a valorização da profissão e os valores sociais. Seguimos Freitas (2000, s/n), que diz: "Ao entrevistarmos professoras aposentadas, pudemos surpreender uma história pessoal se entrecruzando com a coletiva, deixando aflorar importantes questóes que nos ajudaram a melhor compreender a história da Educação... no Brasil”.

\section{Panorama}

Nesse período da década de 1940, a Segunda Guerra Mundial encaminhava-se para o seu final. Houve um enfraquecimento e a queda do nazismo na Alemanha de Hitler (1933-1945), tivemos a ditadura do presidente Getúlio Vargas no Brasil (1930-1945) e o seu fortalecimento durante o chamado Estado novo (1937-1945). O Rio de 
Janeiro, ainda, era o Distrito Federal - capital do Brasil. Foi um tempo em que era incentivado um sentimento de grande orgulho pela pátria.

Foi nesse período histórico que as ex-normalistas da década de 40 construíram a sua identidade pessoal e profissional. Neste contexto, a educação do Instituto vê-se marcada pelos ideais estadonovistas, nos quais contavam a valorização do trabalho, da família, da educação como prática transformadora e impulsionadora de um Brasil que começava a se desenvolver, baseado em uma política de intenso controle social. As educadoras eram formadas com extremo senso de nacionalidade, uma rígida disciplina e estritos valores morais e normas sociais (Schaffel, 1999).

A maior parte dos ex-alunos do Instituto entrevistados tem recordação de uma juventude alegre, encantada pela maravilha de estudar naquela instituição. Insistem em destacar a oportunidade e a honra de estarem ali, o que lhes permitiu ter uma educação de qualidade e um futuro promissor com uma profissão honesta, bem remunerada, útil e reconhecida como fundamental para a sociedade (entrevista coletiva).

O prazer em revelar as inúmeras vivências, de contextualizá-las na busca da reflexão e da crítica, de valorizá-las diante da elaboração do tempo presente, intenta construir o vivido na perspectiva de esclarecer, em parte, o enfrentamento (...) em que as motivações da vida estão intimamente ligadas. O pessoal e o profissional fazem parte de uma totalidade: o eu. (Bastos, 2003, p. 167)

Foi em 1931, quando Anísio Teixeira assumiu o cargo de Direção Geral de Ensino do Distrito Federal, que a escola normal foi transformada em escola de formação de professores, a partir do Decreto n. 3810 de 1932, que ministrava a educação secundária a ambos os sexos, além de preparar professores primários e secundários. Na época da Reforma da Educação, iniciada em 1929, o Instituto de Educação representou um palco para as mudanças que foram propagadas pelos Reformadores da Educação Brasileira. A Reforma de 1932 trouxe a proposta de redefinição da Escola Normal como curso de nível superior (Enéas, 1997).

O Instituto de Educação fica localizado próximo à Praça da Bandeira, na rua Mariz e Barros, n. 273, Rio de Janeiro. O prédio é de 
Memórias e narrativas de professoras "normalistas" do Instituto de Educação/RJ

estilo clássico. Houve um grande cuidado na elaboração de sua estrutura e em suas instalações, buscando, inclusive, a adequação dos espaços às diferentes funções. Segundo os entrevistados, o prédio sempre estava limpo, bem cuidado e conservado, sendo motivo de orgulho da comunidade escolar: "O Instituto, na nossa época, era a nossa casa. Aquele pátio com aquele chafariz no meio... Ah! Muitas histórias na nossa cabeça de coisas que se passaram ali” (primeira depoente).

\section{O livro}

A leitura do livro Era uma vez no Instituto de Educação proporcionou um passeio no tempo, dando-nos a oportunidade de ter acesso a uma cultura escolar relativa à formação de professores, nos anos de 1940, no então Distrito Federal. Os relatos apresentados, além de constituírem memórias do período histórico abordado, forneceram vários pontos interessantes para análise e avaliação dos cursos daquela época, num ambiente de ensino em que autoritarismo e afetividade estiveram o tempo todo mesclados.

Enéas (1997) retrata o Instituto de Educação e registra o cotidiano de preparação para o exercício do magistério das futuras professoras. São relatados os aspectos da educação, das salas de aula, dos objetivos educacionais, a austeridade do ensino e a rigidez metodológica utilizadas não só no ensino como nas avaliações (provas escritas e orais). A motivação das alunas era alimentada pela certeza de estarem sendo bem preparadas para o exercício da profissão, pela admiração despertada na vizinhança, pelo reconhecimento da sociedade quanto à nobre e honrosa missão que era a do professor primário.

O Instituto era destinado à preparação de professoras e professores para as escolas primárias oficiais até 1968, quando o ingresso para o magistério deixou de ser automático. "Era um destino socialmente aprovado e economicamente vantajoso, pois a escolaridade gratuita conduzia a um emprego bem remunerado, sem necessidade de concurso" (Carvalho, 2007, p. 121).

O livro e as entrevistas realizadas nos informam que a incorporação de novas alunas ao Instituto de Educação era um acontecimento comemorado com muita solenidade. A reabertura das aulas despertava um clima de alegria, temor e emoção por parte de todos os presentes. 
No início do ano letivo, a cerimônia de entrada das novas alunas chamava-se incorporação. Solene, organizada com precisão militar, a festa acontecia no pátio principal do Instituto, com o chafariz ao centro. Distância de um braço estendido entre uma aluna e outra. Uniformes impecáveis: saia pregueada de casimira azul-marinho, blusa branca de mangas compridas, cinto sobreposto à blusa, de modo que ficassem aparecendo dois dedos de pano branco sobre a saia escura. Sapato preto e meias brancas. Luvas brancas presas no cinto. As calouras tinham uma tira de cadarço azul marinho no punho da blusa. (Idem, ibid., p. 123-124)

O uniforme que as normalistas usavam despertava orgulho e respeito. Tal garbo pode ser atribuído às dificuldades pela qual passaram antes de serem admitidas. $\mathrm{O}$ respeito ao uniforme, como símbolo de uma conquista, fazia parte do juramento feito no ingresso à Instituição: "O professor era muito valorizado, a normalista era vista de modo diferente (até o uso do uniforme diferenciava as garotas, eram especiais)" (terceira depoente).

O exame de admissão era um processo bastante rigoroso e difícil para as futuras normalistas, exigindo uma forte preparação em cursinhos e muitas horas diárias de estudo. As provas escritas eram penosas, as provas orais sempre muito temidas por serem realizadas na presença de uma banca examinadora exigente e formada por professores catedráticos de cada disciplina.

(...) havia um concurso de admissão altamente seletivo, de modo que proliferavam os cursinhos preparatórios... Já aluna do Instituto, durante algum tempo eu sentia dores de estômago, sempre que o bonde Piedade entrava na Rua Mariz e Barros. Eram as lembranças do exame de admissão. (Carvalho, op. cit., p. 122)

O serviço de saúde era seriamente realizado no Instituto de Educação, tendo uma equipe médica que dispunha de ótimo equipamento para o acompanhamento das condições de saúde dos alunos e para o exame no processo de admissão. $\mathrm{O}$ exame, que acontecia após a aprovação nas provas de conhecimento, era bastante rigoroso e reprovava os candidatos pelas mais simples razões, incluindo algum tipo de deficiência física ou mental e por estarem acima ou abaixo do peso: "Na primeira vez fui reprovada, por ser muito magrinha. Cheguei a pensar em por barrinhas de chumbo na bainha de minha saia, na hora de fazer o segundo exame" (primeira depoente). 
Memórias e narrativas de professoras "normalistas" do Instituto de Educação/RJ

O livro apresenta detalhes das disciplinas que compunham o currículo, que ressaltava a necessidade dos normalistas terem o domínio dos conteúdos e das melhores metodologias de ensino. Na leitura do mesmo, podemos observar diversas mudanças no curso ginasial, se compararmos com os anos seguintes, como a exclusão de algumas matérias (no caso, Latim, Atividades Cívicas e Economia Doméstica) vistas pelas entrevistadas como muito importantes.

Ah! Olha, realmente naquela ocasião havia disciplina, tinha que haver disciplina, mas hoje eu avalio que foi muito importante porque essa parte de civismo toda foi incrementada, era a época da ditadura. Nós tínhamos na Semana da Pátria, o 7 de Setembro e o dia 5... não sei se 5 ou 6 de setembro (era o dia da raça), uma preparação musical, uma beleza de hinos patrióticos e nós cantávamos todos os hinos. O nosso maestro era o Villa Lobos, ele é que fazia os ensaios gerais. (Segunda depoente)

O Latim, por exemplo, era uma disciplina que levava ao melhor entendimento do Português (leitura e escrita). As atividades culturais visavam o desenvolvimento do patriotismo e oportunizavam estudar a diversidade da cultura brasileira, o significado dos hinos em nossa história, cultivando o civismo através do canto orfeônico: "O canto orfeônico fazia parte das aulas, e o local, a sala de música era muito bonita e muito bom de estar" (3a depoente).

Nós tínhamos a professora de música, da turma, mas os ensaios gerais das grandes festas eram preparados pelo Villa Lobos, no estádio de São Januário do Vasco da Gama. Ele era uma brabeza, mas tinha mesmo que ser tudo muito bem preparado porque as festas eram lindas, as minhas recordações são maravilhosas daquela época. (Segunda depoente)

Outra disciplina enfatizada no livro e nas entrevistas era a de Economia Doméstica, na qual se aprendia a trabalhar com as mãos, em coisas úteis para o cotidiano. Outro aspecto marcado era a possibilidade do domínio de duas línguas estrangeiras, o inglês e o francês: "As normalistas adquiriram fluência nessas línguas por terem sido muito bem trabalhadas no Instituto de Educação, não havendo necessidade de aperfeiçoamento fora do âmbito escolar" (terceiro depoente).

$\mathrm{Na}$ entrevista coletiva, foram muitos os que compararam o ensino daquele tempo com o dos dias de hoje, dizendo: 
(...) maioria das escolas atuais oferece a seus alunos somente o inglês, não dando oportunidade de escolha. Isto demonstra a pouca importância dada a outras línguas estrangeiras ou aponta a grande influência que a cultura norte-americana sempre teve em nossa cultura, mostrando a perda que os jovens brasileiros vêm sofrendo, por não serem incentivados a aprender outros idiomas. (Entrevista coletiva) individual:

Este relato corrobora com o que já havia sido dito na entrevista

Eu acho que eu escrevo razoavelmente bem, até hoje, porque, quando entrei para o ginásio se estudava latim, estudava francês, estudava inglês e isso tudo ajudou na formação geral, que foi muito importante para nós. (Segunda depoente)

Hoje em dia o trabalho superficial de leitura e gramática do inglês nas escolas leva os pais a procurarem cursinhos de línguas estrangeiras para que seus filhos se tornem fluentes na única língua oferecida na maioria dos colégios. (Primeira depoente)

Outrora, o próprio Instituto funcionava como laboratório para a aplicação de técnicas que colaborassem na melhoria do ensino das futuras normalistas, requerendo dedicação e constante aperfeiçoamento científico e didático por parte do corpo docente (Schaffel, 1999).

Os conhecimentos adquiridos nas disciplinas do curso normal eram aplicados, inicialmente, nos estágios realizados na escola primária do próprio Instituto. O que, em um momento do curso, passou a se dar, também, em escolas rurais, propiciando às futuras professora um contato mais direto com a realidade em que iriam trabalhar.

Nós só assistíamos às aulas da professora titular. Não interferíamos nem avaliávamos. Em momento nenhum demos aulas, só observávamos a titular. Sem dúvida ficávamos mais seguras. Na prática, aconteceu com tranquilidade. (Terceira depoente)

Nós tínhamos oportunidade de fazer estágio, e fazíamos estágios em escolas da rede pública... Houve uma ocasião, quando estava no normal, que peguei uma turma numa escola próxima ao Instituto (...) numa rua perpendicular à Rua Mariz e Barros, quando uma turma ficou sem professora e nós fomos convidadas, eu fui dar aula lá. Foi um estágio maravilhoso porque foi atuação de campo, foi muito bom. Então, eu acho que o estágio foi muito importante. (Segunda depoente) 
Memórias e narrativas de professoras "normalistas" do Instituto de Educação/RJ

As observações registradas nos relatórios das alunas eram analisadas pela professora orientadora e comentadas em classe. (Primeira depoente)

O rigor das avaliações e dos critérios para aprovação, que incluíam provas mensais, parciais e exames orais, parece ter aguçado a religiosidade de muitas normalistas em sua devoção à Santa Teresinha. Eram comuns as visitas à igreja dedicada à Santa, próximo ao Instituto, nos momentos que antecediam as avaliações (Enéas, 1997).

O livro relata que o civismo era incentivado, inclusive, quando houve o envolvimento das alunas do Instituto no apoio aos pracinhas da Segunda Guerra Mundial, tanto no aspecto material, confeccionando capuzes e luvas, quanto no aspecto psicológico, enviando cartas de estímulo e conforto, além de promoverem campanhas para arrecadação de fundos, o que configurava sua participação ativa e solidária no momento político vivido pelo país.

Claro que eu não fui presa pelo Felinto Müller, não era ativista, era uma adolescente me preparando para ser professora. Então, nós não tínhamos nenhuma repressão política sobre nós, mas havia muita coisa nos porões do Palácio do Catete, coisas feias mesmo. Hoje eu avalio, naquela ocasião, nem imaginava. (Segunda depoente)

A presença do Instituto era marcante, segundo o livro e as entrevistas, em solenidades que ocorriam muitas vezes dentro do próprio estabelecimento. Nessas ocasióes, a presença de figuras célebres no cenário político, como o próprio presidente Getúlio Vargas, era esperada em datas comemorativas, cerimônias, homenagens, entre outros acontecimentos, o que demonstrava o prestígio do Instituto de Educação no cenário nacional.

As festas cívicas eram todas bem preparadas, nós todas de azul e branco sentadas e tinha hora para levantar e formar as palavras Brasil ou Nossa Pátria. Era uma coisa linda, uma coreografia maravilhosa. Para nós era muito gostoso, era uma farra ir ao Vasco (estádio) de bonde para comemorar o dia da raça. (Primeira depoente)

Havia bondes a nossa disposição e iam lotados para São Januário. Nós íamos à festa, havia muita menina que não gostava, mas eu sempre fui muito animada e a minha turma era toda animada. Nós íamos com a maior disposição. Tínhamos lanche, coisas muito gostosas, de modo que era muito bom. Foi um tempo muito bom. (Segunda depoente) 
O livro (Enéas, 1997) e as entrevistadas falam, também, das festas, dos namoros, das recomendações de comportamentos discretos, vozes moderadas, tudo associado às normas de honrar o uniforme:

Tivemos de tudo. No Instituto, tínhamos bailes, já no normal, as Domingueiras Dançantes. Olha, aquilo era uma maravilha, os cadetes, alunos da escola naval (...) já formados, também, muito trem, muitas viagens (...). Íamos lá pra cima (zona rural) e os militares iam, também, da Aeronáutica e do Exército. Houve uma ocasião que fomos muito sacrificadas nos trens superlotados de soldado. Havia um trem especial que ia para a base aérea de Santa Cruz, com os oficiais do exército e os oficiais da aeronáutica, e recebemos passes pra viajar nesse trem. Foi uma namoradeira geral. (Segunda depoente)

Os diretores e professores do Instituto de Educação eram bem preparados para exercer seus cargos, tendo toda uma formação adequada, muitas vezes, no Exterior. Eram muito respeitados por todos (pais, alunos ou funcionários) pelo trabalho exercido no estabelecimento. Nomes famosos como Anísio Teixeira, Villa Lobos, Cecília Meireles e Lourenço Filho integravam a equipe, o que corroborava na construção do prestígio do Instituto em sua época áurea: "O que sempre será lembrado por aqueles que passaram por aquela instituição e mantém um enorme carinho por ela" (primeira depoente).

\section{Visita ao Instituto}

A visita ao Instituto foi realizada em dois momentos (dezembro/ 2008 e junho/2009). Nas duas visitas, a equipe de pesquisa chegou ao Instituto pela manhã e logo observou os detalhes da construção de estilo neocolonial. A visita começou com um passeio pelo prédio, acompanhado pela coordenadora do Cemi. Da entrada do edifício avista-se o pátio interno com o chafariz ao centro, que hoje não funciona mais, mas que já foi ponto de encontro de muitas normalistas.

Quando me deparo com o Instituto, falando no prédio, fisicamente, me deparo quase chorando porque há uma decadência completa. A transformação do Instituto em Faetec... Eu não sei avaliar se foi bom ou não, mas deixar de existir uma escola normal? Podiam fazer a parte técnica toda e manter a escola normal. O Instituto era uma escola que tinha do jardim de infância até o terceiro ano normal. (Primeira depoente) 
Memórias e narrativas de professoras "normalistas" do Instituto de Educação/RJ

Ao redor do prédio, existem largos corredores que dão acesso às salas de aula e um detalhe interessante é que, olhando do pátio para a varanda do terceiro andar, nota-se que as telhas das extremidades têm porcelana na parte de baixo e são pintadas com figuras de corujas azuis, que são o símbolo do professor.

As salas de aula são amplas e foram construídas de forma a garantir a ventilação e a iluminação natural. Os quadros ainda são para uso do giz e as carteiras individuais são de madeira. Todas as paredes são duplas, com mais de 50 centímetros de espessura, o que as torna à prova de som e facilita as aulas. Os corredores, bem espaçosos, foram projetados para que os alunos tivessem a sensação de liberdade total de movimento. São iluminados por janelas no topo da parede, coisa pouco comum na atualidade.

O Laboratório de Ciências possui rico acervo de animais empalhados para os alunos estudarem. O famoso e espaçoso anfiteatro, citado no livro e nas entrevistas diversas vezes, foi restaurado após um incêndio. Nos dias atuais, as cadeiras estão com o estofado rasgado e com o encosto quebrado, o que demonstra que este espaço, tão importante nos aúreos tempos da casa, hoje, está degradado. As quadras desportivas são duas e não escondem os sinais do tempo.

Há muitas colegas minhas, não foi meu caso, que entraram para o Instituto no jardim de infância, fizeram todo o primário, fizeram o concurso para ser normalista e o concurso não era brincadeira, era como o que vocês sofrem hoje no vestibular. Não era fácil entrar para o Instituto, porque nos exames havia muito rigor para selecionar, eram muitos candidatos porque só havia o Instituto, e muito rigor para o preenchimento do número de vagas. Quando eu fiz eram novecentos e tantos candidatos e só entraram duzentos e poucos... Hoje eu não sei se há esse rigor e nem se há ainda escola normal no Instituto. (Segunda depoente)

Há, ainda, a biblioteca e a área da piscina olímpica, localizadas na parte externa do prédio. Dentro da biblioteca funciona o Cemi, local onde está guardada a memória histórica do Instituto. São quadros, imagens, objetos, uniformes, livros. Todo este rico acervo é utilizado em exposições temporárias, exibidas nas vitrines do prédio central. A professora que nos serviu de guia é a curadora de todo o acervo e é quem mantém com carinho o arquivo, organizando e catalogando a documentação recolhida para possibilitar acesso de alunos, professores e pesquisadores. 
Há, ainda, a lanchonete, que não parece pertencer ao prédio. Nos dias das visitas, as alunas que estavam presentes no pátio, apesar de vestirem os mesmos uniformes das normalistas de outrora, não os apresentavam com o mesmo esmero encontrado nas fotos e nos relatos dos velhos tempos.

Para Schaffel (1999), o Instituto funcionava como um laboratório para experimentação dos métodos que melhor correspondiam às necessidades de alunos de todas as idades, inclusive, a da infância. Na tese, a autora traz algumas de suas inquietações e problematiza a questão do modelo de formação oferecido às normalistas daquele período, se ele realmente seria eficaz como modelo de formação-ação e de formação-investigação. Ela ainda nos conduz a uma reflexão:

Quando considero que mesmo não representando um modelo eficaz para a nossa época, pelo menos esta formação deixou sua marca na história do magistério e na história de vida das professoras primárias, transmitindo um saber ser profissional, que mais do que significar objeto da saudade e elogio, deve ser objeto de pesquisa, tema de reflexão nas instituições formadoras de nossos dias, sejam de ensino médio ou superior. (Schaffel, op. cit., p. 150)

Percebemos que, mesmo diante dos limites que perpassam todos os processos e modelos de educação, os mestres-professores formados naquela década foram profissionais comprometidos com a sua prática cotidiana, pois acreditavam em sua profissão e tinham o amplo reconhecimento da sociedade. O Instituto, segundo a autora, tinha sido construído num quadro de transformações ideológicas, políticas e pedagógicas bastante conservador, o que não impediu a criação de novas práticas pedagógicas dentro dos estabelecimentos de ensino.

Outro fator observado, criticamente, na tese (Schaffel, 1999), no livro (Enéas, 1997) e na história de vida das entrevistadas foi a alteração do critério de seleção dos candidatos à carreira do magistério a partir da década de 1970 , privilegiando a carência socioeconômica em detrimento do domínio dos conteúdos.

$\mathrm{Na}$ entrevista coletiva foram pontos críticos de análise: a extinção dos concursos para catedráticos, a eleição para diretores (que não pertenciam ao quadro do Instituto) e outros fatores que provocaram mudanças na formação do corpo docente e discente daquele estabelecimento de ensino. 
Memórias e narrativas de professoras "normalistas" do Instituto de Educação/RJ

Algumas questóes que surgiram voltam à memória, tornando-se indagação: Onde está todo o brilhantismo da profissão? E a valorização da educação brasileira?

\section{Considerações finais}

Chegamos ao século XXI e a realidade de muitas escolas públicas, lamentavelmente, constitui-se de pouco investimento na educação, resultando nas más condiçôes materiais que encontramos. Este é um dos fatores que podem estar diretamente relacionados com o fracasso dos alunos no processo de desenvolvimento da aprendizagem.

Sendo assim, buscamos registrar algumas memórias de profissionais docentes, ex-normalistas do Instituto de Educação, por entendermos que, para pensar mudanças na formação dos atuais professores, precisamos de espaços de reflexão crítica sobre as práticas docentes em diferentes momentos da história da educação brasileira.

Com isso, constatamos que no panorama educacional contemporâneo ocorreram significativas alteraçôes no padrão de qualidade do ensino público em relação à década de 1940 . No entanto, a luta pela qualidade da educação e a sua verdadeira universalização continuam temas de plataformas governamentais por se tratar de um desafio a ser alcançado e, além disso, de uma dívida social que o país tem com a maior parte da população brasileira.

Consultar a tese, ler o livro e outros documentos preservados no Centro de Memória Institucional do Iserj, além de observar o relato das entrevistadas, nos possibilitaram desvendar uma parte da história das normalistas e contemplar parte da história do Instituto de Educação, entendendo a sua importância no contexto histórico-social do Rio de Janeiro, na época Distrito Federal. Ao entrecruzar as histórias e memórias dessas senhoras com a história do Brasil daquele tempo, através de seus próprios relatos, foi-nos possível desvelar um pouco dos contextos em que viviam.

A partir dessa viagem no tempo e numa parte da história da educação brasileira, este se torna um bom momento para pensarmos sobre a educação que queremos e qual o tipo de profissional que podemos ser para alcançarmos o objetivo de uma educação de qualidade e igual para todos. O que fica de aprendizado com esta pesquisa é o que partilhamos com Bastos (2003, p. 170): 
Lembrar não é reviver, mas refazer, repensar, construir com imagens e ideias de hoje as experiências do passado. A construção do passado é relativa, é condicionada pelo presente. É o presente que aponta o que é importante e o que não é, portanto, um interpretar; é quando emergem os efeitos que se podem avaliar os acontecimentos.

\section{Agradecimentos}

Nossa gratidão às professoras Zilá Simas Enéas e Sarita Lea Schaffel por, generosamente, terem nos cedido material para pesquisa. Igualmente, agradecemos às professoras Vera Vasconcellos, Jurema Lopes e novamente Zilá Enéas, por, gentilmente, se disponibilizarem para a realização das entrevistas e, ainda, à professora Heloísa Helena Meirelles, pela atenção em nos orientar nas visitas ao Instituto de Educação.

\section{Notas}

1. Esta disciplina pode ter a duração de seis semestres de curso.

2. As alunas Maria Cecília de Souza Rocha, Suzy Oliveira da Rosa Alves e Thais Freire Silva dos Santos também fizeram parte do grupo de pesquisa.

3. Entrevistadas: Zilá Simas Enéas, Vera Vasconcellos e Jurema Lopes.

\section{Referências}

BASTOS, M.H.C. Memoriais de professoras: reflexões sobre uma proposta. In: MIGNOT, A.C.V.; CUNHA, M.T.S. (Org.). Práticas de memória docente. São Paulo: Cortez, 2003. p. 167- 183. (Coleção "Cultura, memória e currículo", v. 3).

CARVALHO, M. Casa paterna. Rio de Janeiro. Catalogação-na-fonte, 2007.

ENÉAS, Z.S. Era uma vez no Instituto de Educação. Rio de Janeiro: CNEL, 1997.

FREITAS, M.T.A. (Org.). Memórias de professoras: história e histórias. Juiz de Fora: Editora da UFJF, 2000.

SCHAFFEL, S.L. O Instituto de Educação do Rio de Janeiro e a construção 
Memórias e narrativas de professoras "normalistas" do Instituto de Educação/RJ

de uma identidade profissional (1930-1960). 1999. Tese (doutorado em Educação) - Pontifícia Universidade Católica do Rio de Janeiro, Rio de Janeiro.

Recebido em $1^{\circ}$ de setembro de 2010.

Aprovado em 17 de março de 2011. 